\title{
O QUE AS OCUPAÇÕES NOS ENSINAM SOBRE A ADOLESCÊNCIA, O LAÇO SOCIAL E A EDUCAÇÃO?
}

\author{
WHAT OCCUPATIONS TEACH US ABOUT ADOLESCENCE, \\ THE SOCIAL BOND AND EDUCATION?
}

\section{¿QUÉ OCUPACIONES NOS ENSEÑAN ACERCA DE LA ADOLESCENCIA, EL LAZO SOCIAL Y LA EDUCACIÓN?}

Luciana Gageiro Coutinho
Claudia Braga de Andrade

\begin{abstract}
RESUMO
Este artigo busca refletir sobre o movimento das ocupações das escolas ressaltando a inovação que essa experiência traz para se repensar a escolarização de jovens, sobretudo nos laços que podem ser estabelecidos entre os jovens e a escola. A partir das contribuições teóricas da psicanálise a respeito do mal-estar na cultura e nos modos de fazer frente a ele, articulamos a noção de laço social com as ocupações, privilegiando dois eixos de análise fundamentais: 1) como esses novos laços sociais internos e externos contribuem para a sustentação de um novo ideal de escola; 2) de que modo essa nova configuração social presente no contexto das ocupações nos permite pensar sobre a relação entre transmissão do conhecimento e desejo de saber no espaço escolar.Por fim, destacamos que as ocupações inauguram um modo de fazer laço na escola através de uma nova posição discursiva na qual os estudantes podem estar presentes enquanto sujeitos desejantes que reivindicam e recriam a escola.
\end{abstract}

PALAVRAS-CHAVE: Laço social. Educação. Adolescência. Ocupações

\section{ABSTRACT}

This article seeks to reflect on the movement of the occupations of the schools emphasizing the innovation that this experience brings to rethink the schooling of young people, especially in the bonds that can be established between the young people and the school.

From the theoretical contributions of psychoanalysis to malaise in culture and ways of dealing with it, we articulate the notion of social bond with occupations, favoring two fundamental axes of analysis: 1) how these new bonds internal and external social contributions contribute to the support of a new school ideal; 2) so this new social configuration present in the context of occupations allows us to think about the relation between transmission of knowledge and desire to know in the school space.

\footnotetext{
${ }^{1}$ Doutora em Psicologia - Pontifícia Universidade Católica do Rio de Janeiro (Puc-Rio). Professora Adjunta IV da Faculdade de Educação da Universidade Federal Fluminense (UFF). Email: lugageiro@uol.com.br

${ }^{2}$ Doutora em Teoria Psicanalítica - Universidade Federal do Rio de Janeiro (UFRJ). Professora Adjunta do Departamento de Educação da Universidade Federal de Ouro Preto (UFOP), Ouro Preto, MG. Email: cb.andrade@terra.com.br
}

Submetido em: 24/11/2016 - Aceito em: 12/02/2017

(C) ETD-Educação Temática Digital Campinas, SP v.19 n.esp. p. 48-63 jan./mar. 2017 
Finally, we emphasize that the occupations inaugurate a way of making tie in the school through a new discursive position in which the students can be present as desiring subjects that claim and recreate the school.

KEYWORDS: Social bond. Education. Adolescence. Occupations RESUMEN

Este artículo tiene como objetivo reflexionar sobre el movimiento de las ocupaciones de escuelas que enfatizan la innovación que esta experiencia lleva a repensar la educación de los jóvenes, especialmente los lazos que se pueden establecer entre los jóvenes y la escuela.

A partir de los aportes teóricos del psicoanálisis sobre el malestar en la cultura y las formas de hacer frente a ella, articular la noción de vínculo social con las ocupaciones, haciendo hincapié en dos ejes fundamentales de análisis: 1) ¿Cómo estos nuevos lazos interna y externa sociales contribuyen al sostenimiento de un nuevo ideal de la escuela; 2 ) por lo que este nuevo entorno social esto en el contexto de las ocupaciones nos permite pensar acerca de la relación entre la transmisión del conocimiento y el deseo de saber en la escuela.

Por último, destacamos que las ocupaciones inauguran una manera de hacer que encaje en la escuela a través de una nueva posición discursiva en la que los estudiantes pueden estar presentes como sujetos deseantes que dicen y recrean la escuela.

PALABRAS CLAVE: Lazo social. Educación. Adolescencia. Ocupaciones

\section{INTRODUÇÃO}

As ocupações das escolas feitas nos últimos meses por estudantes do Ensino Médio em diversas regiões do Brasil - em protesto ao plano de reorganização da rede pública de Educação - têm nos instigado a pensar a partir de diversos pontos de vista, já que se trata de um fenômeno novo e de muita potência diante do cenário tão desanimador do país. No campo da psicanálise e educação, somos levados a pensar sobre o que tal experiência pôde mostrar sobre a possibilidade de transformações nos laços sociais dentro da escola e fora dela, bem como sobre como pode se dar uma mudança na esfera da relação dos estudantes envolvidos com o conhecimento. Mais especificamente, por se tratar de adolescentes, tão comumente descritos como aqueles que mais recusam ou resistem à escolarização, como pensar sobre a verdadeira virada nesse cenário ao qual assistimos nesses últimos meses? Adolescentes exigindo melhores condições de ensino, querendo estar na escola, cuidar dela e ávidos e abertos para conhecer tudo o que lhes é oferecido pela comunidade e pelos docentes que os apoiaram.

Neste artigo, vamos explorar, a partir de um olhar sobre uma experiência de ocupação, os laços sociais presentes nesse contexto, seja entre os próprios ocupantes, seja no que diz respeito à relação deles com os representantes da instituição escolar ou, ainda, no que diz respeito à sustentação desse fenômeno pela comunidade do entorno da escola. Assim, visamos pensar sobre a inovação que essa experiência traz para a reflexão sobre a escolarização de jovens, sem nos concentrar em só um dos polos desse campo, ou seja, nem nos jovens nem na escola, mas nos laços que podem se estabelecer entre ambos.

(C) ETD-Educação Temática Digital Campinas, SP v.19 n.esp. p. 48-63 jan./mar. 2017 
Pensando a partir das contribuições teóricas da psicanálise a respeito do mal-estar na cultura e nos modos de fazer frente a ele, trabalharemos com algumas hipóteses freudianas a respeito do laço social (Freud, [1913] 1976; [1921] 1976; [1930] 1976) para refletir sobre as ocupações, privilegiando dois eixos de análise fundamentais: 1 ) como esses novos laços sociais internos e externos contribuem para a sustentação de um novo ideal de escola; 2) de que modo essa nova configuração social presente no contexto das ocupações nos permite pensar sobre a relação entre transmissão do conhecimento e desejo de saber.

\section{UMA EXPERIÊNCIA DE OCUPAÇÃO ESCOLAR}

Entre os meses de março e junho de 2016, cerca de 70 escolas da rede pública do Rio de Janeiro estiveram ocupadas por estudantes, em sua maioria do Ensino Médio destas mesmas instituições. As ocupações se iniciaram em apoio à greve dos docentes da rede estadual, mas se constituíram como um movimento à parte com suas assembleias e pautas próprias. Durante as ocupações, as escolas se mantiveram abertas para receberem doações, visitas e contribuições de diversas ordens de membros da comunidade de seu entorno. As questões de base deste artigo foram construídas a partir de visitas e do desenvolvimento de algumas atividades em escolas ocupadas, inspiradas no paradigma da pesquisa-intervenção (BESSET \& CASTRO, 2008). Isso se deu com mais frequência em uma escola estadual situada na zona sul do Rio de Janeiro, na qual foram realizadas várias visitas informais e duas rodas de conversa com estudantes previamente agendadas em acordo com os ocupantes, que nos serviram como material fundamental para a reflexão apresentada neste artigo. Descreveremos aqui um pouco do que foi observado e, em seguida, os pontos que se destacaram como questões de interesse a serem investigadas.

Trata-se de uma escola de grande porte, onde estudam cerca de dois mil alunos de Ensino Médio, na qual a ocupação contou com a participação de cerca de 400 estudantes em frequência diária. Apenas um pequeno grupo dormia efetivamente na escola, mas esse número não nos foi revelado por razões de segurança, no dizer dos próprios estudantes. Durante a ocupação, a escola era gerida principalmente por esse grupo menor, que se subdividia em várias comissões: a recepção, a cozinha, a limpeza, a segurança, a comunicação e o conteúdo pedagógico. Quase sempre os jovens se mantinham no mesmo comitê ao longo de toda a ocupação, pois achavam que isso facilitava o aprendizado e a execução das tarefas. Mas, quando necessário, eram feitas trocas ou outros vinham ajudar a um comitê específico em um momento de maior necessidade, como era o caso da cozinha em momentos de grande movimento no horário das refeições. Havia um respeito absoluto pelo trabalho de cada comitê. Por exemplo, no caso do comitê de recepção, este possuía legitimidade e autoridade até mesmo para barrar a entrada e a saída de estudantes da escola em momentos de maior tensão com os grupos contra a ocupação. Ao mesmo tempo, afirmavam sempre que quem está na frente são todos e a responsabilidade também é de todos. No relato sobre o trabalho coletivo e a dinâmica dos comitês destacaram o sentimento de empatia pelo colega ou pelos funcionários da escola. Além disso, falaram da

(C) ETD-Educação Temática Digital Campinas, SP v.19 n.esp. p. 48-63 jan./mar. 2017 
aprendizagem que obtiveram no desafio de cozinhar para tantos, de manter o prédio limpo, de lidar com os improvisos no cancelamento de uma aula para a qual havia muitos estudantes esperando, enfim, nas atividades que remetem ao dia a dia da escola, pareciam compartilhar de um sentimento de cumplicidade com a administração e com a gestão da escola. Ao se referirem a um inspetor da escola, o nomearam como "o cara que é o dono do cadeado mais amado do mundo".

Durante uma das rodas de conversa realizada nessa escola, a maioria dos ocupantes presentes relatou que não conhecia antes os outros com os quais estava convivendo na ocupação, já que eram de turmas ou até mesmo de turnos diferentes na escola. Segundo o relato dos jovens, dessa e de outras escolas, muitos dos ocupantes eram estudantes com sérios impasses na escolarização. Presenciamos o relato de um deles que estava pensando em abandonar a escola um pouco antes da ocupação e ao final desse período disse que mudou radicalmente sua posição.

Fica evidente para nós que, durante a ocupação, houve uma circulação nos lugares cristalizados anteriormente ocupados pelos jovens dentro da escola e que essa nova experiência promoveu novos laços sociais e novas posições discursivas nas relações já estabelecidas. Isso também se deu no âmbito externo às escolas. Seja nas reuniões do comando das ocupações, onde os jovens das escolas particulares da zona sul eram vistos inicialmente como os "coxinhas" pelos jovens da periferia, o que era estranho para eles que sempre eram vistos como os "favelados" ao circularem nas redondezas de suas escolas; seja no âmbito das relações internas à escola. Com as ocupações, tanto as escolas públicas de diferentes regiões do estado puderam se conectar quanto muitos jovens de escolas particulares também puderam se aproximar das escolas ocupadas, em um encontro que afirmavam ser inédito. Por ocasião de visitas às escolas ocupadas, estudantes de escolas públicas e particulares trocaram informações sobre a formação de grêmio, sobre as disciplinas, provas, horários, rotinas escolares, o que também trouxe alguns estranhamentos e descobertas. Pudemos presenciar um desses episódios quando, junto com os jovens da escola que frequentávamos, organizamos uma roda de conversa com jovens de escolas particulares da cidade que foram convidados para a atividade e depois mantiveram contato e intercâmbio com a ocupação.

Outro ponto interessante observado foi a relação com as aulas e o conhecimento transmitido pelos voluntários que se ofereceram para contribuir com diversas atividades durante as ocupações. Na escola visitada foram oferecidas desde atividades mais próximas ao currículo escolar, tais como "aulões" de matemática, física, filosofia, história, a oficinas de yoga, poesia, fotografia, rodas de conversa etc. Segundo o relato dos ocupantes, a frequência e a participação nas atividades era surpreendente em comparação à rotina da escola em seu funcionamento regular. Os estudantes nos contaram com surpresa e estranhamento entre eles que, mesmo quando estavam jogando na quadra, ao serem chamados para uma aula de matemática, os ocupantes foram sem resistência e com prazer.

(C) ETD-Educação Temática Digital Campinas, SP v.19 $\quad$ n.esp. $\quad$ p. 48-63 jan./mar. 2017 
Encontramos no pátio central da escola o mural que reuniu as mensagens sobre o significado da ocupação (FIGURA 1).

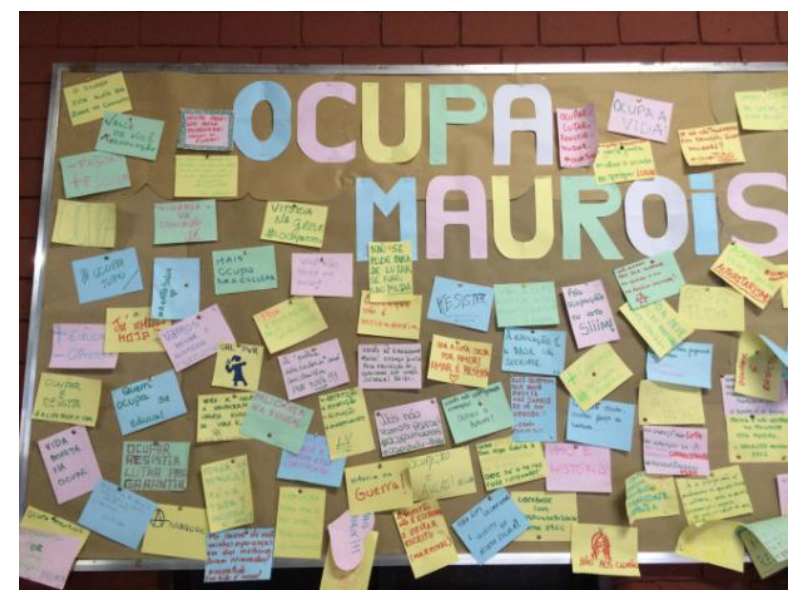

FIGURA.1 - Mural do pátio central da escola durante a ocupação Fonte: https://www.facebook.com/ocupaandremaurois/

No manifesto escrito durante a ocupação dessa escola, os estudantes reivindicaram um aumento da carga horária nas disciplinas de sociologia, filosofia e espanhol, além da extinção do SAERJ, um simulado unificado que vinha pronto para a rede com o qual eles trabalhavam, tirando a autonomia local das escolas e dos professores. Esta autonomia também foi reivindicada e, nesse ponto, atendida após a ocupação, com a conquista do direito de eleger os diretores. O que pensar dessas reivindicações? Para além do momento da ocupação propriamente dita, parece que os jovens nos dão indícios de um desejo de ocupar um outro lugar nessas instituições, talvez menos passivo e contido, tal como tradicionalmente se espera do estudante. Algumas falas dos estudantes da escola que frequentamos sobre o que teriam aprendido com a ocupação estavam escritas em pequenos cartazes e foram postadas na página do Facebook, criada durante o movimento, também nos instigam a pensar nas relações entre a adolescência, a educação e o laço social.

(C) ETD-Educação Temática Digital Campinas, SP v.19 n.esp. p. 48-63 jan./mar. 2017 


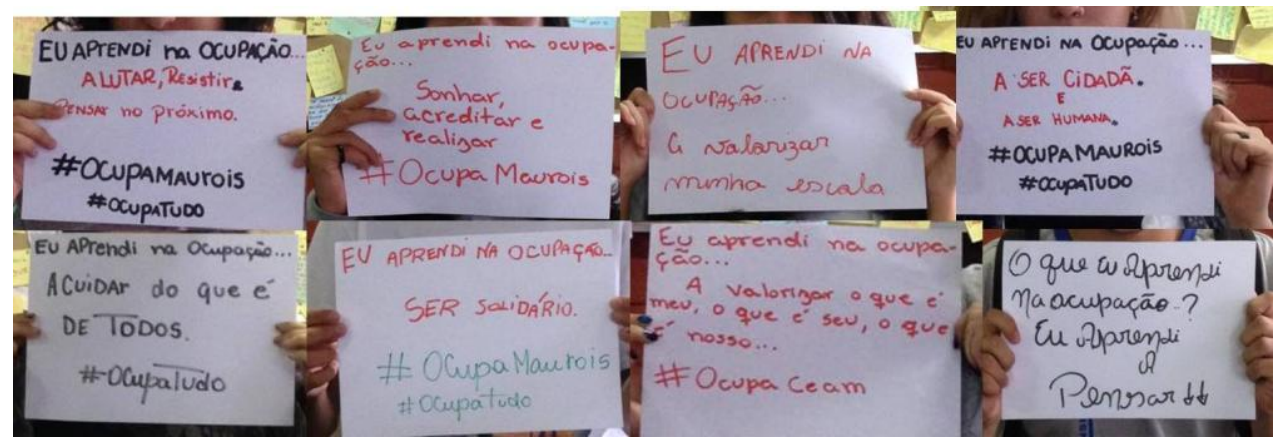

FIGURA 2 - Timeline Facebook Escola André Maurois Fonte: https://www.facebook.com/ocupaandremaurois/

"Na ocupação eu aprendi: a lutar, resistir e pensar no próximo"

"Na ocupação eu aprendi: a sonhar, acreditar e realizar"

"Na ocupação eu aprendi: a valorizar minha escola"

"Na ocupação eu aprendi: a ser cidadã e ser humana"

"Na ocupação eu aprendi: a cuidar do que é de todos"

"Na ocupação eu aprendi: a ser solidário"

"Na ocupação eu aprendi: a valorizar o que é meu, o que é seu, o que é nosso"

\section{A OCUPAÇÃO: NOVOS PACTOS SOCIAIS}

O acompanhamento dessa experiência relatada acima nos leva a supor que a ocupação repercute psiquicamente nesses jovens como um processo de apropriação criativa do espaço escolar. As falas acima nos fazem pensar no trabalho de reelaboração de ideais sociais na adolescência, a começar pelo ideal de escola que recriam e compartilham através desse movimento, trabalho esse que não se dá sem a existência de laços de identificação horizontais (FREUD, 1921/1976).

Para Freud, o conceito de ideal do eu inaugura um caminho fundamental para o estudo do laço social pela psicanálise. Em suas próprias palavras:

O ideal do ego desvenda um importante panorama para a compreensão da psicologia de grupo. Além do seu aspecto individual, esse ideal tem seu aspecto social; constitui também o ideal comum de uma família, uma classe ou uma nação (FREUD, [1914a] 1976, p.119).

(c) ETD-Educação Temática Digital Campinas, SP v.19 n.esp. p. $48-63$ jan./mar. 2017 
Tomando por base essa premissa, Freud propõe no texto Psicologia das Massas e Análise do Eu ([1921] 1976) um modelo explicativo para os laços sociais nas massas pautados em dois eixos de sustentação fundamentais: o eixo vertical da relação ao líder ou o ideal compartilhado por todos os membros e o eixo horizontal das identificações entre aqueles que compartilham desse objeto/ideal comum.

Seguindo a trilha já inaugurada em Totem e tabu ([1913]1976), onde Freud constrói uma teoria a respeito da gênese do laço social através de construções da cultura que remetem ao poder originário e mítico do pai da horda, o conceito de ideal introduz, entretanto, uma outra dimensão na compreensão do laço social. Como bem observa Assoun (1983), é através da idealização de um objeto ou ideia, bem como pelas identificações possibilitadas pelo reconhecimento desse objeto comum que o ideal social sustenta a realidade coletiva e torna possível o laço entre os homens. Assim, Assoun ressalta que o esquema do laço social proposto por Freud em 1921 desliza da problemática proeminente da interdição marcada em 1913 para a questão da idealização. Segundo ele, o que Freud acentua em 1921 é a legitimação do interdito paterno pelos próprios sujeitos através da idealização. Alguns anos mais tarde, Freud avança nessa direção afirmando também que os ideais estão também na base das ilusões religiosas ([1927]1976). A partir disso, a cultura pode ser entendida como uma construção comum, que permite aos sujeitos lidarem com as tensões e insatisfações próprias à pulsão através dos ideais.

Voltando ao território da escola com Freud, vale evocar a conferência proferida por ele em 1914 na cerimônia de comemoração de 50 anos do colégio em que estudou. Nessa conferência, Freud afirma que, nos seus anos de jovem estudante, mais importante para o seu futuro interesse pela ciência, foi a sua relação com os professores e com os outros alunos, do que o conteúdo daquilo que lhe foi transmitido.

É nessa fase do desenvolvimento de um jovem que ele entra em contato com os professores, de maneira que agora podemos entender a nossa relação com eles (...). Foi por isso que, embora ainda bastante jovens, impressionaram-nos como tão maduros e tão inatingivelmente adultos. Transferimos para eles o respeito e as expectativas ligadas ao pai onisciente de nossa infância e depois começamos a tratá-los como tratávamos o nosso pai em casa (FREUD, [1914b] 1976, p. 288).

Assim lembra Freud que, em seu tempo de jovem estudante, "algo" era atribuído, por ele, aos professores que os colocava em um lugar de destaque, e assim nos dá notícias sobre os laços afetivos nos quais se sustenta a autoridade do professor em sala de aula, de forma similar ao que também constatou em relação ao lugar ocupado pelo analista numa análise. Na conferência, Freud chega a observar que o professor muitas vezes assume o lugar de "pai substituto", depositário de um ideal de eu que já não mais se sustenta nas figuras de identificação da infância. Entretanto, ao final da conferência, Freud faz menção ao fato de que, para além do eixo vertical da relação com os professores, a escola é o espaço para a atualização das experiências fraternais, no eixo das relações horizontais que

(C) ETD-Educação Temática Digital Campinas, SP v.19 n.esp. p. 48-63 jan./mar. 2017 
são estabelecidas com os colegas. Este ponto não é desenvolvido por Freud, mas ele não deixa de marcá-lo como algo que seria merecedor de uma análise futura.

A importância dos laços horizontais na sustentação do laço social, que remetem aos laços entre os irmãos no mito da horda primeva descrito por Freud ([1913] 1976), é bastante enfatizada por Kehl (2000) quando propõe uma "função fraterna" no psiquismo.

Se o ato dos irmãos, no mito das origens, instituiu a função paterna, é a partir da cultura, da linguagem, que esta função continua operando. O pai real e as diversas autoridades que podem substituí-lo não fazem mais do que transmitir a Lei - à qual também estão sujeitos... assujeitados. Separar o pai real do pai simbólico equivale, na ontogênese, ao assassinato primordial; refazer na vida pessoal o percurso da horda primitiva à coletividade civilizada é tarefa que não se realiza sem a participação do semelhante (KEHL, 2000, p.35).

Conforme comenta Kehl, no percurso do mito freudiano de 1913, o eixo horizontal das relações entre os irmãos é fundamental, desde a cumplicidade necessária para o crime contra o pai até a tarefa de separar o pai real do pai simbólico, garantida pelas identificações fraternas mediadas pelo ideal. Dessa forma, o que ela questiona é se a função paterna é capaz de operar se não for elaborada de forma coletiva e sustentada através das identificações horizontais entre os irmãos. Como observa Kehl (2000), as identificações horizontais, típicas da fratria, dependem da relação vertical ao pai, mas fazem a ela uma suplência indispensável, o que, segundo ela, pode ser pensado em termos de traços identificatórios secundários em relação à identificação primária ao pai.

Isso se daria, de acordo com Kehl (2000), quando cada um entre os 'pares' passasse a se apropriar do que foi herdado, já que, se por um lado a fratria produz a orfandade simbólica dos seus membros, também lhes fornece algum amparo, alguma pertinência extrafamiliar. A relação entre o grupo de 'pares' passa a funcionar como uma garantia de reconhecimento de traços identificatórios, de modo que é na fratria que os adolescentes muitas vezes encontram uma ancoragem para o trabalho de elaboração dos ideais na adolescência. No caso das ocupações, esse trabalho incide sobre as possibilidades de reinvenção da escola que coincidem com o momento da reinvenção de si e do outro, típicas da adolescência.

Algo que nos surpreendeu nas conversas com os ocupantes é que a organização para a divisão de tarefas se realizava praticamente de maneira espontânea, sem a imposição ou a fixação de responsabilidades previamente estabelecidas. Quando Ihes perguntamos se havia um revezamento fixado ou combinado, eles simplesmente nos responderam que todos eram responsáveis por tudo. Isso de fato nos faz pensar que as reponsabilidades e as funções de "comando" circulavam com relativa liberdade e espontaneidade entre eles, sendo a representatividade dos lugares imediatamente reconhecida e respeitada pelos

(C) ETD-Educação Temática Digital Campinas, SP v.19 n.esp. p. $48-63$ jan./mar. 2017 
outros. Nada mais contrastante com a fragilidade da autoridade que a escola e os professores vivenciam no seu cotidiano regular, fora da ocupação. Como pensar tal contraste a partir do argumento freudiano a respeito do pacto social?

Como já trabalhamos anteriormente (Coutinho, 2009), pensamos que a insistência freudiana no eixo vertical da organização social, representado originalmente pela figura do pai da horda e, posteriormente, pelo ideal, acabou por negligenciar outros modos de constituição social, como também observam Roudinesco \& Plon (1998) e Kehl (2000). Assim, uma das marcas da fratria é o reconhecimento do desamparo por parte dos irmãos, o que faz com que a rivalidade seja matizada pela necessária renúncia à satisfação imediata das pulsões e pela experiência do necessário apoio mútuo, sustentado através de pactos e de construção de referências comuns no plano da cultura (ideais, religião, instituições etc.). Nesse sentido, os laços fraternais, diferente dos laços horizontais totalitários, regidos pela onipotência narcísica do eu ideal, implicam no reconhecimento do desamparo e das diferenças de cada um, e apostam no viver coletivo como construção de caminhos comuns possíveis na sustentação do desejo pautado pelo registro do ideal do eu, sempre inatingível, mas apontando um caminho a ser percorrido (COUTINHO, 2009).

Cabe observar aqui o relato dos jovens a respeito do acolhimento às diferenças como marca do funcionamento dos laços entre os ocupantes que, muitas vezes, nem se conheciam antes da ocupação ou, ainda, faziam parte de grupos diversos com histórias prévias de antagonismos e implicâncias típicas do "narcisismo das pequenas diferenças". Isso fica evidente tanto no que diz respeito aos novos arranjos nas relações que passam a ocorrer entre eles dentro da escola quanto em relação aos novos laços que eles passam a estabelecer com jovens de fora da escola, seja com aqueles de outras ocupações, seja com jovens de escolas particulares que frequentam ou apoiam o movimento. De modo semelhante, isso também se faz notar com os estudantes que apresentavam dificuldades de inserção no grupo escolar e passaram a se envolver de modo diferente com a escola e com os colegas a partir das ocupações. Podemos pensar que o que ocorre então com a ocupação é uma reconfiguração dos modos de fazer laço, já que agora a construção do projeto comum do movimento como eixo transversal parece ser preponderante em relação às identificações narcísicas especulares que visam apenas à certificação de si através da inclusão do idêntico e da exclusão do diferente.

Podemos supor então, a partir da observação desse movimento, que a experiência da fraternidade pode funcionar como o espaço ético para a formação de laços sociais não totalitários na escola. O conceito de fraternidade se tornou uma questão presente na atualidade e objeto de reanálise por Birman (2003), que destaca a importância de reintroduzir o conceito para refletir as novas condições de mal-estar na atualidade e indica que o conceito deve ser tratado no plural a fim de indicar que existem diferentes modalidades de fraternidades. Para o autor, a interpretação dos laços fraternos supõe uma consideração crítica sobre os destinos da paternidade na subjetividade moderna. Destacar a abrangência do laço social no psiquismo para além da dinâmica edipiana seria uma forma de

(C) ETD-Educação Temática Digital Campinas, SP v.19 n.esp. p. 48-63 jan./mar. 2017 
se deslocar da versão rivalitária ou mortífera da fraternidade e considerar também suas dimensões éticas e políticas.

Esta questão também é discutida por Kehl (2000) ao reintroduzir a ideia de fratria para examinar os outros modos de operação da relação do sujeito com os semelhantes, presentes no nosso cotidiano. A autora chama a atenção para o termo 'função' que demarca justamente o seu caráter necessário da participação do semelhante na constituição do sujeito. No entanto, reforça a possibilidade de renovar os termos do pacto civilizatório quando a 'circulação horizontal' pode funcionar como um tipo de vínculo social no qual a transmissão de experiências e produção discursiva podem ocorrer entre semelhantes e a submissão voluntária pode ser relativizada (KEHL, 2000).

\section{TRANSMISSÃO E DESEJO DE SABER}

Do ponto de vista da psicanálise, o laço social se articula ao mal-estar na cultura, já que, se por um lado viver em sociedade implica em conviver com o mal-estar inevitável, por outro, é também a partir da cultura que se pode encontrar modos de tratá-lo (Freud, [1930]1976). A complexidade que envolve o relacionamento com os outros foi o que Freud destacou como a maior fonte de sofrimento humano na sociedade moderna que, no entanto, trouxe também enormes ganhos para a vida humana em sua relação com a natureza. A escola como espaço público concentra um grande campo de articulações entre estudantes, professores, funcionários, comunidade, família que compõem uma rede de relacionamentos diferenciados em relação ao outro. Este mosaico, do qual a escola é suporte, funciona como produtor de mal-estar nos laços sociais. No entanto, é a partir da possibilidade de se suportar esse mal-estar no encontro com os outros, que o sujeito pode construir saídas para o seu desejo. Compreendemos que o movimento da ocupação demonstrou a possibilidade dos sujeitos desejantes ali presentes, com voz ativa, esboçarem um modo de fazer laço social inédito. Se o trabalho de subjetivação da adolescência depende das experiências do jovem no espaço público, isso reforça a importância do espaço escolar como uma de suas possíveis realizações, pois só este permite tanto reunir os sujeitos humanos em sua diversidade quanto separá-los. Dessa forma, a escola como espaço público pode se constituir em um verdadeiro espaço transicional na adolescência, no sentido winnicottiano, que, tal como o brincar na infância, fornece um meio fecundo para o exercício das singularidades, sempre referidas a uma coletividade. (WINNICOTT, [1953]1975).

No relato dos jovens ocupantes observados, pudemos notar que, apesar das controvérsias e críticas a respeito dela, a escola ainda ocupa o lugar de referência para eles, representando um ideal cultural sustentado a partir de um pacto social que extrapola os muros escolares. Foi possível notar a valorização e a identificação dos estudantes com o espaço escolar. Chama a atenção a foto escolhida como capa no perfil do Facebook "Andre Maurois em luta" criado durante o movimento das ocupações.

(C) ETD- Educação Temática Digital Campinas, SP v.19 n.esp. p. 48-63 jan./mar. 2017 


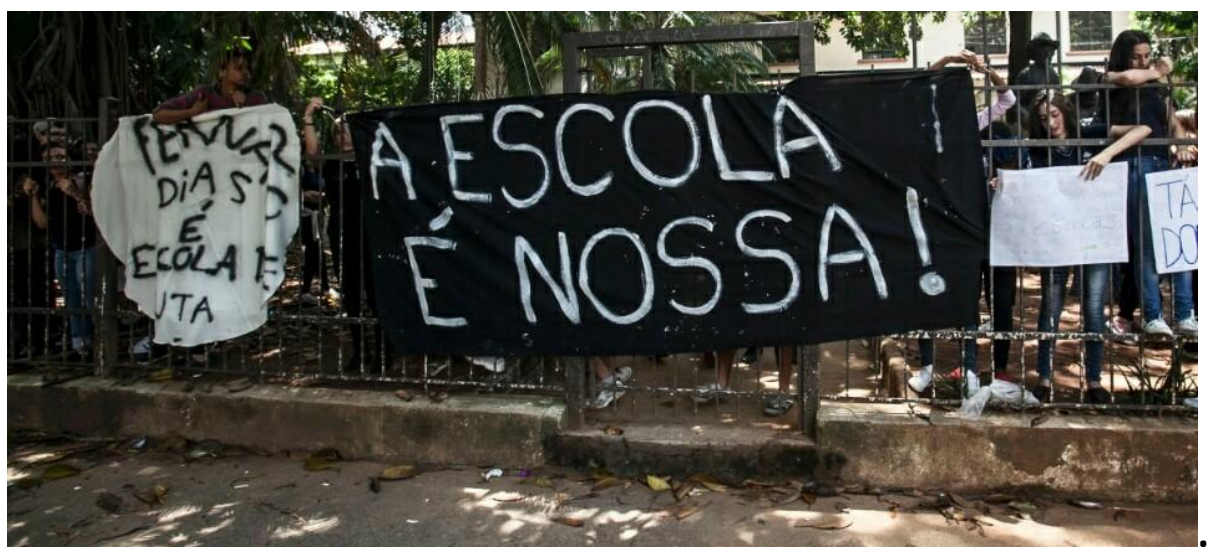

FIGURA.3 - Foto de capa do Facebook, Perfil André Maurois em luta Fonte: https://www.facebook.com/ocupaandremaurois/

A afirmativa "a escola é nossa" parece expressar bem a reivindicação dos jovens, o sentimento de pertencimento e o seu desejo de se 'reapropriar' da escola. Foi a partir deste lugar, de identificação com a escola, que se iniciou um forte diálogo com a comunidade: moradores vizinhos, estudantes e professores de escolas particulares próximas, construindo pouco a pouco novos espaços de trocas coletivas.

Reconhecemos na fala dos estudantes um fenômeno instigante que remete ao desejo de revitalizar a escola e à afirmação do seu lugar como um ideal social. Se o movimento da ocupação resistiu, sobretudo, à escola disciplinada e à sua hierarquização, a sua vocação de se constituir como um espaço de construção/transmissão de saber foi preservado durante a ocupação, com uma intensa programação diária de aulas, oficinas e rodas de conversa entre os estudantes, professores e convidados. Mas como se ocupou este espaço? De formas variadas, aula de física, história, geografia, conversa sobre relações internacionais, aulas temáticas, como humanas com funk, espaço aberto para discussão sobre 'a educação que queremos', debate sobre drogas, exibição de filmes e curtas, apresentações culturais diversas, entre muitas outras atividades.

(C) ETD-Educação Temática Digital Campinas, SP v.19 $\quad$ n.esp. $\quad$ p. $48-63 \quad$ jan./mar. 2017 


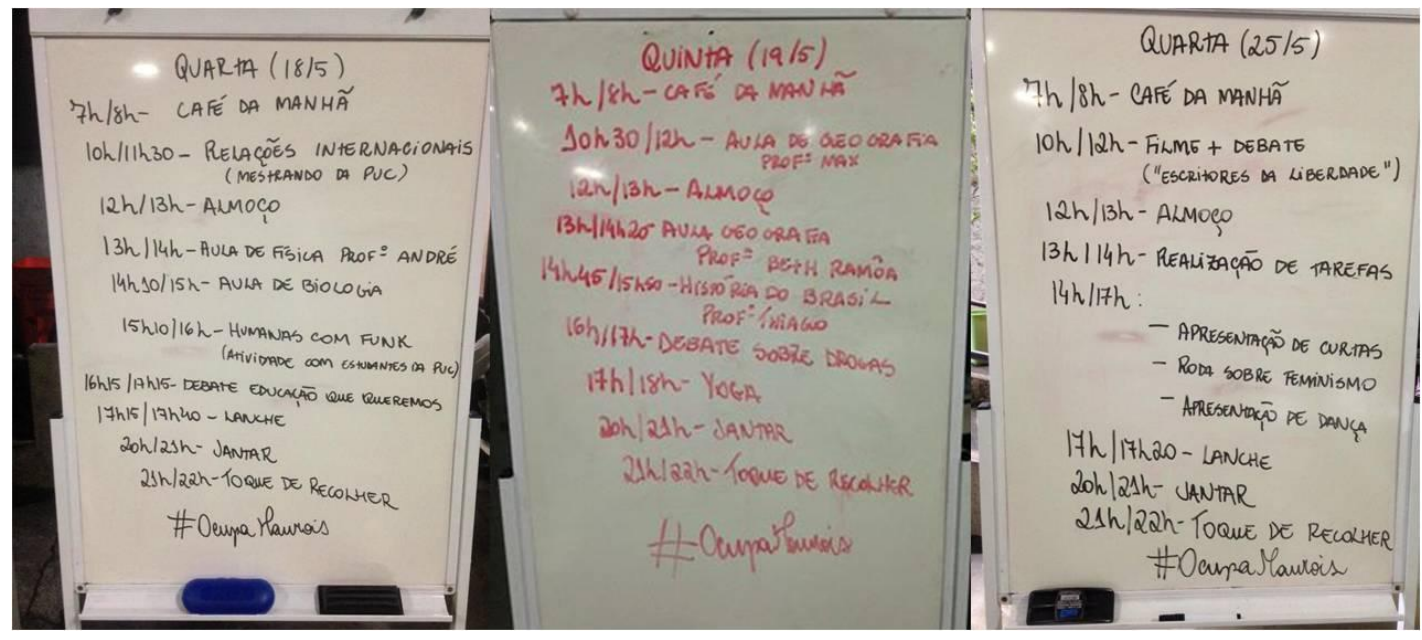

FIGURA 4 - Quadro de divulgação da programação diária durante a ocupação Fonte: https://www.facebook.com/ocupaandremaurois/

O ato de ocupação é um acontecimento que traz uma aposta na escola como espaço de troca ao construir propostas/saídas para o que se expressa tão frequentemente nas afirmativas de que a escola está em crise ou que a escola é uma tecnologia de época que está em desajuste com a vida do jovem na contemporaneidade. Paula Sibilia (2012), ao repensar a escola nos dias hoje, lança o questionamento de até que ponto o dispositivo da escola seria uma aparelhagem incompatível com os corpos e subjetividades, uma vez que a categoria aluno e professor, assim como as formas de transmissão de conhecimento, foram completamente revisadas. Segundo a autora, é partir desta constatação de uma defasagem ou mesmo de um mal-entendido entre a subjetividade daqueles que supostamente não aprendem e daqueles que pretendem ensinar que se busca tecer estratégias capazes de consumar a experiência da aprendizagem, valorizando redes que vão além dos muros escolares. A reapropriação da escola pelos estudantes indica a vitalidade de outros dispositivos de aprendizagem possíveis.

A partir da observação das experiências de ocupação das escolas pelos jovens nos últimos meses, gostaríamos de enfatizar as mudanças nos laços sociais entre estudantes e entre estudantes/escola/professor ou, ainda, entre estudantes/sociedade que parecem ter surpreendido a todos - vide os diversos ensaios publicados em jornais de notícias - e nos trouxeram muitas interrogações e reflexões. A propósito, o depoimento do sociólogo francês Dubet (1997) traz reflexões que parecem já apontar para alguns pontos evidenciados nas ocupações. A partir de sua experiência, ao se aventurar a sair de seu lugar de renomado professor universitário e ir atuar como professor de adolescentes em uma escola da periferia de Bordeaux, Dubet acentua a importância de algum tipo de intervenção visando à relação entre os adolescentes e a escola, reconhecendo que, para além da hipótese da desinstitucionalização, a escola ainda é uma importante agência socializadora para adolescentes, embora a forma pela qual isso se dê possa ter mudado. Dito isso, ele propõe a necessária existência de verdadeiros "contratos de vida em comum" entre os

(C) ETD-Educação Temática Digital Campinas, SP v.19 n.esp. p. $48-63 \quad$ jan./mar. 2017 
professores e os adolescentes, com direitos e deveres para ambos. Assim, a experiência das ocupações nos remete ao argumento de Dubet em favor de um trabalho possível e necessário a ser feito de (re)construção de acordos e laços na escola e com a escola, de uma nova contratualidade a ser instaurada em permanência a partir dos encontros e dos confrontos que lá se dão, que possa dar lugar talvez a novos ideais coletivamente sustentados, psicanaliticamente falando, em lugar de uma hierarquia estabelecida a priori tal como já se deu anteriormente.

Parece-nos que a experiência das ocupações deixa claro que a hierarquia escolar estabelecida se contrasta com a vivacidade dos laços e das funções instituídas e instituintes nascidas neste novo cenário. Se entendemos que a autoridade e os ideais compartilhados pelo grupo se sustentam também nos laços horizontais entre os estudantes, podemos talvez compreender como esse lugar foi rapidamente concedido a alguém que se oferece a ensinar alguma coisa a eles e cujo convite é aceito pelos adolescentes. Possivelmente, pelo novíssimo pacto que foi capaz de se estabelecer, a relação com as aulas e com aqueles que ofereciam as atividades durante a ocupação era muito diferente da relação usual com os professores.

Porém, o que eles nos instigam a pensar é que tal pacto se encontra por demais burocratizado e deslegitimado. Precisa ser renovado e revitalizado para que a escola deixe de ser reconhecida como um lugar de interdições sem sentido, servidão, disciplina, anonimato e possa funcionar como autoridade pactuada já que abriga e viabiliza ideais compartilhados socialmente.

Quando nos perguntamos como a experiência da ocupação nos ensina outros modos de ensinar e aprender, bem como as suas relações com as produções de subjetividades, encontramos no 'Ocupa Escola', um movimento que se propõe literalmente a ocupar o espaço da escola recriando os espaços de trocas de saber e de construção de laço social, nos quais o estudante não se coloca submisso à produção de saber cientificista, mas como um sujeito desejante, propondo e assumindo novos pactos sociais.

\section{CONSIDERAÇÕES FINAIS}

A experiência das ocupações nos remete fortemente aos laços fraternais que se estabelecem entre os estudantes nas escolas ocupadas, bem como entre eles e a comunidade externa à escola que também apoia e participa das ocupações, e à função que estes desempenham na subjetivação adolescente no entrecruzamento entre questões psíquicas, políticas e sociais. Talvez possamos supor, portanto, que as ocupações nos ensinam a importância de se refazer os pactos e laços que legitimam a escola em seu lugar de transmissão e construção de conhecimento. E que isso não se dá sem a participação dos sujeitos nela envolvidos, nem sem os laços horizontais que sustentam o projeto da escola que se deseja no coletivo. Assim, as ocupações inauguram um modo de fazer laço na escola através de uma nova posição discursiva na qual os estudantes podem estar presentes como

(C) ETD-Educação Temática Digital Campinas, SP v.19 $\quad$ n.esp. $\quad$ p. 48-63 jan./mar. 2017 
sujeitos desejantes que reivindicam e recriam a escola. Desejo que é motor de transformações discursivas e promotor de identificações horizontais que dão sustentação à reinvenção do pacto pela educação.

\section{REFERÊNCIAS}

ASSOUN, P.L. L’Entendement Freudien - Logos et Ananké. Paris: Gallimard, 1983.

BIRMAN, J. Fraternidades: Destinos e Impasses da Figura do Pai na Atualidade. PHYSIS:

Revista de Saúde Coletiva. Rio de Janeiro, 13(1): p.93-114, 2003.

CASTRO, L. R., BESSET, V. L. (orgs.) Pesquisa-Intervenção na Infância e Juventude. Rio de Janeiro: Nau, 2008.

COUTINHO, L.G. Adolescência e Errância: Destinos do laço Social Contemporâneo. Rio de Janeiro: Editora Nau: 2009.

DUBET, F. Quando o sociólogo quer saber o que é ser professor. Revista Brasileira de Educação, (5/6), p.222-230, 1997.

FACEBOOK, André Maurois em luta. Disponível em:

<https://www.facebook.com/ocupaandremaurois/>. Acesso em: 20 nov. 2016.

FREUD, S. (1913). Totem e Tabu. Obras Completas de Sigmund Freud, ESB, vol. XIV. Rio de Janeiro: Imago, 1976.

(1914a). Sobre o narcisismo: uma introdução. Obras Completas de Sigmund Freud, ESB, vol. XIV. Rio de Janeiro: Imago, 1976.

(1914b). Algumas reflexões sobre a psicologia escolar. Obras Completas de Sigmund Freud, ESB, vol. XIII. Rio de Janeiro: Imago, 1976.

. (1921). Psicologia de grupo e análise do ego. Obras Completas de Sigmund Freud, ESB, vol. XIII. Rio de Janeiro: Imago, 1976.

(1927). O futuro de uma ilusão. Obras Completas de Sigmund Freud, ESB, vol. XX, Rio de Janeiro: Imago, 1976.

(1930). O mal-estar na civilização. Obras Completas de Sigmund Freud, ESB,

volume XXI. Rio de Janeiro: Imago, 1976.

KEHL, M.R. (org) Função fraterna. Rio de Janeiro: Relume Dumará, 2000.

ROUDINESCO, E.\& PLON, M. Dicionário de Psicanálise. Rio de Janeiro: Jorge Zahar Editor, 1998.

SIBILIA, P. Redes ou paredes: a escola em tempos de dispersão. Rio de Janeiro: Contraponto, 2012.

(C) ETD-Educação Temática Digital Campinas, SP v.19 $\quad$ n.esp. $\quad$ p. 48-63 jan./mar. 2017 
WINNICOTT, D. (1953). Objetos transicionais e fenômenos transicionais. O brincar e a realidade. Rio de Janeiro: Imago, p.7-44, 1975.

\footnotetext{
' Revisão gramatical do texto por: Tânia Cristina Belarmino Silva
} 